\title{
Percepção de virtudes morais organizacionais: Evidências de validade de um instrumento de medida para o contexto brasileiro
}

\author{
Perception of organizational moral virtues: Evidence of validity of a \\ measurement instrument for the brazilian context \\ Percepción de virtudes morales organizacionales: Evidencias de la validez de \\ un instrumento de medida para el contexto brasileño
}

\author{
Sinésio GOMIDE Júnior ${ }^{1}$ \\ Lorrana Ellen VIEIRA \\ Áurea de Fátima OLIVEIRA \\ Universidade Federal de Uberlândia, Uberlândia, MG, Brasil
}

Resumo Este trabalho parte do pressuposto de que os vínculos morais do indivíduo com seu sistema empregador podem ser afetados pela sua percepção de que esse sistema tem virtudes que norteiam seu comportamento frente a seus empregados e clientes. A literatura brasileira não disponibiliza um instrumento para mensurar essa percepção junto aos empregados. Assim, este estudo teve como objetivo a busca pelas evidências de validade de um instrumento de medida sobre a percepção de virtudes morais organizacionais, cujos resultados revelaram três fatores: "boa-fé organizacional", "confiança organizacional" e "generosidade organizacional". Os autores sugerem que pesquisas posteriores investiguem outras formas de validação, na busca de consolidação do construto na literatura da área do comportamento organizacional.

Palavras-chave:

Virtudes; ética; análise fatorial.

Abstract This work starts from the assumption that the individual's moral ties with the employment system may be affected by the individual's perception that this system has virtues that guide its behavior in relation to its employees and customers. The Brazilian literature does not provide an instrument to measure this perception, regarding employees. Thus, the aim of this study was to search for evidence of validity of a measurement instrument on the perception of organizational moral values, whose results showed it was formed by three factors: "organizational goodwill", "organizational trustworthiness", and "organizational generosity". The authors suggest that further investigations try finding other ways of validation, seeking the consolidation of the construct within the area of Organizational Behavior.

Keywords:

Virtues; ethics; factor analysis.

Resumen Este trabajo parte de la hipótesis de que los lazos normativos del individuo con su sistema empleador pueden ser afectados por la percepción de que este sistema tiene virtudes que guían su conducta frente a sus empleados y clientes. La literatura brasileña no ofrece instrumentos para mensurar esa percepción para los empleados. Así, el presente estudio tuvo como objetivo la búsqueda de evidencias de validez de un instrumento de medida sobre la percepción de virtudes morales organizacionales, cuyos resultados revelaron tres factores: "la buena fe organizacional", "confianza organizacional" y "generosidad organizacional". Los autores sugieren que investigaciones futuras estudien otras formas de validación, con vistas a la consolidación del constructo en la literatura del área del comportamiento organizacional.

Palabras-clave:

Virtudes; ética; análisis factorial. 
$\mathrm{F}$ rente a um ambiente organizacional em que a confiança vem se deteriorando, cabe aos estudiosos da pesquisa organizacional estender suas investigações em campos que representem qualidades enobrecedoras, propósitos significativos e o mais alto potencial humano - o estudo das virtudes nas organizações (Cameron, Bright, \& Caza, 2004). Gavin e Mason (2004) afirmam que os indivíduos que passam muito tempo no trabalho veem na organização a fonte de muitas de suas relações interpessoais, sociais e políticas. Moore e Beadle (2006) comentam que as organizações podem funcionar como uma pessoa moral ou ainda que, ao terem algo análogo ao caráter, podem ser avaliadas como virtuosas ou viciosas ou mesmo serem caracterizadas como um personagem moral localizado nesses dois extremos. Para os autores, a organização é vista como um lugar onde as virtudes são necessárias para que ela possa se envolver em práticas de excelência.

Segundo Cameron et al. (2004), as virtudes têm sido estudadas na perspectiva do indivíduo, posição compartilhada por Comte-Sponville (2009) ao considerar que a virtude é "uma maneira de ser, mas adquirida e duradoura, é o que somos [...] porque assim nos tornamos” (p. 9). Contudo, os autores realçam que as virtudes têm relação com exigências culturais e Comte-Sponville (2009) acrescenta, ainda, o fator biológico. Portanto, as virtudes aprendidas nos contextos histórico e cultural são importantes nessa construção. Cameron et al. (2004) afirmam que em nível agregado, as virtudes têm sido associadas às organizações, comunidades e culturas. A justificativa para essa afirmação apoia-se na economia e na sociologia, pois a prosperidade de uma economia e a própria longevidade de uma sociedade dependem das virtudes, posto que sua existência implica na internalização de normas morais necessárias à estabilidade e à harmonia social.

As virtuosidades organizacionais referem-se a contextos organizacionais nos quais virtudes são praticadas, apoiadas, alimentadas, disseminadas e mantidas, considerando tanto o nível individual quanto o coletivo (Cameron et al., 2004). Ribeiro e Rego (2010), baseando-se no trabalho de Cameron e colaboradores, propõem dois componentes das virtuosidades organizacionais: (a) virtuosidade nas organizações, que se refere a comportamentos virtuosos dos membros organizacionais; (b) virtuosidade através de organizações, que se refere às características das organizações que estimulam ou facilitam a virtuosidade dos indivíduos.

Diversos autores tratam da importância do estudo das virtudes no âmbito organizacional (Arruda, Whitaker, \& Ramos, 2009; Ferrell, Fraedrich, \& Ferrell, 2001; Fonseca, 2011; Sertek \& Reis, 2002; Wright \& Goodstein, 2007). Entretanto, estudos empíricos que procuram unir esses dois domínios são escassos (Cameron et al., 2004; Kooshki \& Zeinabadi, 2015; Ribeiro \& Rego, 2010). Cameron et al. (2004) afirmam que atribuir a qualidade das virtudes a uma organização significa ela as estimula em seus membros. Os autores esclarecem que a virtuosidade não se trata de uma condição do tipo tudo ou nada, pois tanto as pessoas quanto as organizações não são completamente virtuosas o tempo todo. Na ausência de um único indicador, os autores postulam que "uma definição geral de virtuosidade organizacional [...] inclui as ações de indivíduos, atividades coletivas, atributos culturais ou processos que habilitem a disseminação e a perpetuação da virtuosidade em uma organização" (Cameron et al., 2004, p. 3). O instrumento construído por esses autores é composto por cinco dimensões (confiança, integridade, perdão, compaixão e otimismo) que mantiveram relações significativas com níveis mais elevados de desempenho.

Em Portugal, Ribeiro e Rego (2010), com o intuito de desenvolver mais pesquisas sobre o tema, procuraram relacionar a percepção de virtuosidade organizacional com o comprometimento organizacional e comportamentos de cidadania organizacional (altruísmo, desportivismo, cortesia, conscienciosidade e virtude cívica). Os resultados indicaram que o comprometimento organizacional normativo mediava a relação entre a percepção de virtuosidade global (medida criada pelos autores para representar os cinco fatores em conjunto) e o altruísmo (fator do comportamento de cidadania organizacional). $\mathrm{Na}$ Nigéria, Ugwu (2012) relacionou percepções de virtuosidade organizacional e otimismo a percepções de engajamento no trabalho. Os resultados apontaram, via análise de regressão múltipla hierárquica, que ambos os regressores eram fortes preditores do engajamento.

Por um lado, nota-se que os estudos sobre o tema se encontram pouco desenvolvidos tanto teórica quanto empiricamente (Cameron et al., 2004; Hamrahi, Najlfbagy, Musakhani, Daneshfard, \& Delavar, 2015). Por outro, pressupor que as virtudes organizacionais podem afetar o comprometimento normativo do indivíduo com a organização representa uma perspectiva importante de investigação, ainda pouco explorada (Meyer, Stanley, Hersconvitch, \& Topolnytsky, 2002). Assim, é possível supor que um conjunto de princípios, regras, normas, metas e valores organizacionais, quando interiorizado pelo indivíduo, se constituiria como a base de 
seu compromisso moral com uma organização. Virtudes morais encontram-se entre essas bases, conforme Ribeiro e Rego (2010).

A ética e a moral têm sido objeto de reflexão de vários ramos das ciências humanas, da religião e da filosofia. No âmbito organizacional, a preocupação com a ética e a moral corporativas vem crescendo desde o final do século XX (Ferrell et al., 2001). Srour (2000) define moral como a adoção de um conjunto de valores e regras de comportamento por coletividades, nações, categorias sociais, comunidades ou organizações. Já ética refere-se à disciplina teórica, ao estudo sistemático que tem como objeto de análise as morais, a moralidade, os fenômenos morais, os fatos sociais regulados por normas morais ou submetidos a avaliações morais (Srour, 2000).

De acordo com Vásquez (1997), além da delimitação entre os termos ética e moral, é importante ressaltar que nas relações cotidianas, os indivíduos se deparam com problemas práticos, tomadas de decisão e ações de diferentes tipos. Para resolvê-los, os sujeitos recorrem a normas que julgam serem mais adequadas ou dignas de cumprimento, formulam juízos, avaliam as decisões e, às vezes, buscam determinados argumentos ou razões para justificar a decisão adotada ou os passos dados. Dessa forma, como assinalam Ferrell et al. (2001), torna-se necessário conhecer as filosofias morais, definidas pelos autores como "princípios ou regras que o indivíduo emprega para decidir o que é certo ou errado (se configurando) como perspectivas morais ideais que proporcionam princípios abstratos para orientar a vida social do indivíduo” (p. 50). Os autores desenvolvem uma discussão sobre perspectivas teóricas que estão mais voltadas ao campo empresarial. Entre as filosofias morais, destaca-se a ética da virtude segundo a qual "a virtude moral é uma disposição adquirida e valorizada como uma parte do caráter do indivíduo" (p. 57). Pode, ainda, ser considerada uma postura que o sujeito desenvolve por meio da prática e do compromisso. Ferrell et al. (2001) indicam que as virtudes consistem em "um conjunto de constantes que permanecem as mesmas, quaisquer que sejam as normas culturais dinâmicas, as regras ou outras pessoas" (p. 61).

A ética das virtudes remonta às ideias de Aristóteles (2006), segundo as quais a finalidade da vida humana é alcançar a felicidade ou "vida boa" (eudamonia). Para alcançá-la, é necessário viver racionalmente, o que implica viver segundo a virtude, caracterizada como o meio termo entre ações opostas, o excesso e a deficiência, a justa proporção entre as emoções e as ações. A virtude não é inata ao homem, mas é adquirida por meio da prática e do hábito. Assim, os homens não agem corretamente porque têm virtudes, mas as têm porque agem corretamente. Vásquez (1997), por sua vez, define a virtude como a capacidade ou a potência moral do indivíduo, que supõe uma disposição estável ou constante de agir moralmente de maneira positiva, ou seja, de querer o bem. Já o oposto da virtude é o vício, que também é considerado uma disposição uniforme e continuada de querer o mal.

Assim, a definição de virtudes diz respeito às "qualidades morais, adquiridas pelo indivíduo, nele presentes como uma disposição caracterológica que se atualiza ou realiza numa situação concreta" (Vásquez, 1997, p. 180). Contudo, um ato moral ou uma reação, isolados e esporádicos, não são suficientes para que determinado traço de caráter seja atribuído. Como afirmava Aristóteles (2006), a virtude é um hábito, isto é, um tipo de comportamento que se repete ou uma disposição adquirida e uniforme de agir. Para Aristóteles, é a prática de atos justos, moderados ou corajosos que tornam os indivíduos justos, moderados ou corajosos.

Assim, o sujeito contribui para a realização da moral mediante atos cotidianos e repetidos, que decorrem de uma disposição ou capacidade de agir de modo permanente e estável, a fim de fazer o bem e de se comportar moralmente em um sentido válido. Definida dessa forma, a virtude se relaciona com o valor moral, visto que os valores envolvem a compreensão em que se fundamentam as normas morais que guiam e orientam a realização do ato moral (Vásquez, 1997). Entretanto, além dessas características, a virtude "supõe a decisão - ou força de vontade necessária - para superar os obstáculos que se interponham à sua realização” (p. 180).

La Taille (2002) também contribui para a discussão entre virtudes e valores ao estabelecer três tipos de valores relacionados à representação que o indivíduo tem de si: os valores não morais, como a beleza, a fama ou a glória; valores imorais, como, ser violento; e valores coerentes com as regras morais, como a justiça. Além desses valores congruentes com as regras morais, há valores que conferem sentido às regras morais, garantem sua aplicação e ampliam a significação humana, que são as virtudes. La Taille (2001) discute, ainda, sobre quais dessas virtudes poderiam ser consideradas virtudes morais. De acordo com o autor, o conceito de virtudes pode ser caracterizado de duas maneiras: a primeira refere-se à "função de determinado objeto" (p. 90) e segunda diz respeito às "qualidades que uma pessoa pode possuir e que lhe conferem valor, despertando a admiração alheia [...] e, dentro dessas qualidades, algumas ocupam lugar especial, pois remetem ao caráter da pessoa" (p. 91). 
Pieta (2009), fundamentada nas proposições de La Taille (2001), afirma que essas virtudes de caráter (gratidão, justiça, generosidade e coragem) podem ser entendidas como virtudes morais. Por fim, como assinala Vásquez (1997), da mesma forma que o caráter do indivíduo está sob influência do meio social em que vive, seus traços de caráter, e com eles suas virtudes morais, se mostrarão ou serão adquiridas no meio social em que está inserido. Assim, as qualidades morais, ou virtudes, necessitam de condições sociais favoráveis para que floresçam. Dessa maneira, a aquisição e o cultivo de determinadas virtudes morais "se verificam num contexto social concreto e, portanto, são favorecidas ou freadas pela existência de determinadas condições, relações e instituições sociais" (Vásquez, 1997, p. 182). Para o autor, virtudes como a solidariedade, a ajuda mútua, o companheirismo, a cooperação e a disciplina consciente podem guiar os homens.

As virtudes dizem respeito, portanto, a uma disposição ou capacidade do indivíduo se manter em um sentido moralmente válido a fim de alcançar o bem, a vida boa ou a excelência, estando relacionadas a qualidades que se referem ao caráter moral do sujeito. Apesar de o conceito de virtude não ter sido muito modificado desde a antiguidade até os tempos de hoje, ainda não há um consenso sobre o número exato de virtudes entre os autores (Comte-Sponville, 2009; Hamrahi et al., 2015; MacIntyre, 2001; Vásquez, 1997). No Brasil, Gomide (2011) propõe, em estudo minucioso que vislumbra, na formação de indivíduos virtuosos, duas pré-virtudes (polidez e obediência), seis virtudes (justiça, empatia, generosidade, honestidade, verdade/mentira e amizade), dois sentimentos morais (vergonha e culpa) e dois processos envolvidos nessa formação (reparação de dano e perdão). O estudo detalha as virtudes, os sentimentos e os processos considerados "boas qualidades [...] norteadoras das relações sociais e da conduta dos homens" (p. 262) que inspiram o cultivo e a manutenção das relações humanas. Virtudes semelhantes são encontradas nas proposições teóricas de Ferrell et al. (2001), que mencionam a participação de virtudes como empatia, equidade, veracidade, confiança e autocontrole na determinação das relações empresariais e que dão suporte ao ambiente organizacional.

A partir da literatura consultada, este estudo tem como objetivo a construção e a busca de evidências de validação de um instrumento de medida de percepção de virtudes morais organizacionais, inédito na literatura brasileira. Para isso, partirá das proposições teóricas de Ferrell et al. (2001) e Gomide (2011) para estabelecer o número de dimensões que constituem esse fenômeno e dos fundamentos de La Taille $(2001,2002)$ e Vásquez (1997) para a conceituação de virtudes morais. Parte-se da premissa, demonstrada no levantamento teórico que subsidia este trabalho, que a conceituação de virtudes encontra, na literatura, um contorno consensual que não se repete no número de virtudes elencadas (Cameron et al., 2004; Comte-Sponville, 2009; Gomide, 2011; Hamrahi et al., 2015; MacIntyre, 2001; Vásquez, 1997). Dessa forma, este trabalho partiu de proposições presentes em duas obras (Ferrell et al., 2001; Gomide, 2011), editadas no Brasil, para a elaboração dos itens que compuseram as dimensões do instrumento de medida. Além disso, o instrumento final aferirá, com maior propriedade, as percepções de trabalhadores brasileiros, em possível contraposição aos trabalhadores norteamericanos (Cameron et al., 2004) e portugueses (Ribeiro \& Rego, 2010).

\section{MÉTODO}

A partir da investigação teórica foram identificadas oito dimensões arroladas por Ferrell et al. (2001) e Gomide (2011): amizade, autocontrole, confiança, empatia, generosidade, honestidade, veracidade e equidade. Apenas com base nas oito dimensões definidas nos trabalhos de Ferrell et al. (2001) e Gomide (2011), foram elaborados 35 itens, submetidos à avaliação de dez juízes (professores de graduação e pós-graduação e alunos de pós-graduação stricto sensu do curso de psicologia de uma instituição federal de ensino superior). As dimensões apresentadas aos juízes foram as seguintes: (a) amizade: crença do funcionário de que a organização que o emprega tem capacidade progressiva em estabelecer relações, de forma autônoma, com base na aceitação, compreensão e apoio; (b) autocontrole: crença do funcionário de que a organização que o emprega tem capacidade de evitar a vantagem, o prazer imediato ou a exploração de uma oportunidade de satisfação do autointeresse; (c) confiança: crença do funcionário de que a organização que o emprega tem disposição/capacidade de acreditar no comportamento futuro de outros, havendo expectativa de que a promessa ou o acordo sejam cumpridos; (d) empatia: crença do funcionário de que a organização que o emprega tem capacidade de compreender e, ao mesmo tempo, expressar compreensão sobre a perspectiva e os sentimentos de outro; (e) equidade: crença do funcionário de que a organização que o emprega tem capacidade de respeitar os direitos das pessoas, atribuindo a cada indivíduo o que lhe cabe ou compete; (f) generosidade: crença do funcionário de que a organização que o emprega tem disposição espontânea em ajudar/beneficiar o outro, sem esperar retornos, pagamentos ou 
quaisquer retribuições em troca; (g) honestidade: crença do funcionário de que a organização que o emprega tem capacidade de comportar-se, voluntariamente, de acordo com o que é correto, conforme uma ética socialmente aceita ou estabelecida; e (h) veracidade: crença do funcionário de que a organização que o emprega tem disposição em fornecer dados ou informações corretas ao indivíduo, conforme a realidade.

Dos 35 itens submetidos à avaliação dos juízes, 30 foram considerados representativos das dimensões definidas, com índices de concordância entre os juízes acima de 70\% (Pasquali, 1999), sendo os demais descartados. Posteriormente, seguiu-se o procedimento de validação por meio da aplicação do instrumento composto por 30 itens.

\section{Participantes}

A amostra foi composta por 227 trabalhadores que tinham vínculo de trabalho formal, sendo 56,38\% $(n=129)$ do sexo feminino com idade média igual a 36,03 anos $(D P=11,64)$ e tempo médio de trabalho de 15,90 anos $(D P=11,09)$. A maioria dos participantes tinha grau de instrução equivalente ou superior ao ensino superior $(51,1 \% ; n=117)$ e estavam vinculados a organizações públicas do estado de Minas Gerais (50,7\%; $n=115)$. Predominaram na amostra trabalhadores que classificam sua área de atuação como prestação de serviços (73,6\%; $n=167)$. Pasquali (2003) recomenda uma representação de cinco sujeitos para cada item do instrumento. Assim, o tamanho da amostra foi apropriado, havendo sete indivíduos por item.

\section{Procedimento de coleta de dados e cuidados éticos}

Foram explicados os objetivos e o caráter acadêmico para as pessoas que aceitaram participar deste estudo, assim como a voluntariedade de suas atividades. O Termo de Consentimento Livre e Esclarecido foi apresentado em duas vias, sendo que uma delas permaneceu com o participante e a outra foi arquivada pelos pesquisadores. Os participantes foram abordados em horários nos quais estavam fora de seus ambientes de trabalho e foi combinado o local e a data para recolhimento dos questionários. Este estudo foi aprovado pelo Comitê de Ética sob protocolo no 203.453.

Foram utilizados questionários autoaplicáveis, com itens fechados, em versão impressa, aplicados individualmente. Os participantes da pesquisa deveriam marcar, para cada um dos itens, um número em uma escala Likert de quatro pontos, variando de 1 (discordo totalmente) a 4 (concordo totalmente).

\section{Procedimento de análise de dados}

Para análise dos dados, utilizou-se o programa estatístico SPSS (Statistical Package of Social Science) versão 18.0. Para extração dos fatores foi realizada análise dos componentes principais (Principal Components - PC). Três tipos de critérios foram utilizados: (a) convencional - autovalores superiores a um e a indicação do scree plot; (b) estatístico - análise paralela de Horn que indica o número de fatores com precisão de 92\% (Laros, 2004) - essa análise compara os autovalores obtidos na análise dos componentes principais com autovalores aleatórios, obtidos por meio do programa RanEign; e (c) relevância do fator - índices de variância inferior a 3\% de variância total indica que o fator é irrelevante (Harman, 1967).

A etapa seguinte foi confirmar a estrutura fatorial por meio do método de fatoração dos eixos principais (Principal Axis Factoring - PAF), com rotação oblíqua. Segundo Laros (2004), "procedimentos de rotação oblíqua podem conduzir a uma estrutura simples mais convincente e melhor interpretável do que uma solução ortogonal" (p.185). O autor recomenda que a correlação entre fatores não deve ser baixa, ou seja, inferior a 0,30, o que tornaria a rotação ortogonal adequada. A carga fatorial mínima inicial foi igual a 0,30 , índice necessário para que o item seja considerado um representante útil do fator (Pasquali, 1999). Por fim, a confiabilidade foi verificada por meio do cálculo do alfa de Cronbach.

\section{RESULTADOS}

$\mathrm{Na}$ aplicação da análise fatorial exploratória, como primeiro passo, o programa foi ajustado para o método denominado Principal Components (PC), sem nenhuma rotação designada, com o estabelecimento padrão (default) de encontrar autovalores iguais ou maiores que 1 (um) e a carga fatorial a partir de 0,30. A medida de adequação da amostra de Kaiser-Meyer-Olkin (KMO) foi de 0,94 e do teste de esfericidade de Bartllet's $\left(\chi^{2}=4441,031\right.$, com $\left.p<0,001\right)$ indicaram que a análise fatorial poderia ser executada. Os resultados indicaram cinco componentes, mas suas composições mostraram-se inviáveis, considerando os indicativos do scree plot. 
Em seguida, a fim de alcançar maior precisão da solução fatorial, foram adotados critérios mais rígidos, como autovalores iguais ou maiores que 1,5 e cargas fatoriais iguais ou maiores que 0,40 . Utilizando-se o método dos componentes principais, três fatores foram identificados.

Em seguida, para confirmar o número de fatores por meio da análise paralela, o software RanEigen (Enzmann, 1997) foi utilizado para uma amostra de 227 sujeitos e 30 variáveis. Verificou-se que a partir do quarto componente o autovalor aleatório passou a ser maior do que o empírico. Desse modo, o cálculo indicou que as correlações a partir do quarto componente eram espúrias. Portanto, o banco de dados teria até três componentes. A partir dessas análises, foram extraídos três fatores pelo método de Análise dos Eixos Principais, com rotação oblíqua. As correlações entre os fatores variaram de 0,34 a 0,58 , confirmando a adequação quanto à escolha do método de rotação. Os três fatores extraídos explicam $58,89 \%$ da variância acumulada dos itens.

A consistência interna dos três conjuntos de itens pertencentes a cada um dos três fatores foi verificada por meio do cálculo dos índices de alfa de Cronbach. O fator 1 apresentou o nível mais elevado e satisfatório de fidedignidade, com índice de 0,95; o fator 2 também revelou índice elevado de fidedignidade de 0,92 e, por último, o fator 3 apresentou o menor alfa, com índice de 0,80. Este último, embora menor, apresentou um índice satisfatório, situado acima do limite inferior estabelecido como aceitável $(0,70)$ indicado por Hair, Anderson, Tatham e Black (2005). A Tabela 1 apresenta os fatores, as cargas fatoriais dos itens, os valores de comunalidade e as correlações item-total da solução trifatorial do instrumento.

TABELA 1. Itens de percepção de virtudes morais organizacionais, cargas fatoriais, comunalidades e correlações item-total

\begin{tabular}{|c|c|c|c|c|c|}
\hline Itens & $\mathbf{F 1}$ & F2 & F3 & $h^{2}$ & CIT \\
\hline $\begin{array}{l}\text { 1. Estabelece relações de aceitação com } \\
\text { seus empregados. }\end{array}$ & 0,66 & & & 0,45 & 0,63 \\
\hline $\begin{array}{l}\text { 2. Dá assistência aos seus empregados, } \\
\text { independentemente de qualquer regra ou } \\
\text { acordo estabelecido. }\end{array}$ & 0,54 & & & 0,40 & 0,63 \\
\hline 4. Age de forma ética. & 0,84 & & & 0,21 & 0,71 \\
\hline $\begin{array}{l}\text { 6. Distingue o que é certo e o que é errado } \\
\text { em suas condutas. }\end{array}$ & 0,66 & & & 0,58 & 0,70 \\
\hline $\begin{array}{l}\text { 8. Compreende os sentimentos de seus em- } \\
\text { pregados. }\end{array}$ & 0,62 & & & 0,53 & 0,73 \\
\hline $\begin{array}{l}\text { 9. Fornece informações precisas de sua re- } \\
\text { alidade. }\end{array}$ & 0,74 & & & 0,49 & 0,71 \\
\hline $\begin{array}{l}\text { 10. Fornece informações verdadeiras de sua } \\
\text { realidade. }\end{array}$ & 0,84 & & & 0,49 & 0,74 \\
\hline $\begin{array}{l}\text { 11. Expressa a compreensão das perspecti- } \\
\text { vas de seus empregados. }\end{array}$ & 0,65 & & & 0,58 & 0,75 \\
\hline 12. Respeita os direitos dos empregados. & 0,84 & & & 0,55 & 0,75 \\
\hline $\begin{array}{l}\text { 13. Atribui, a cada empregado, o que lhe é } \\
\text { de direito. }\end{array}$ & 0,73 & & & 0,60 & 0,68 \\
\hline $\begin{array}{l}\text { 16. Estabelece relações de cooperação com } \\
\text { seus empregados. }\end{array}$ & 0,73 & & & 0,57 & 0,72 \\
\hline $\begin{array}{l}\text { 17. Expressa a compreensão dos sentimen- } \\
\text { tos de seus empregados. }\end{array}$ & 0,67 & & & 0,61 & 0,79 \\
\hline $\begin{array}{l}\text { 18. Fornece informações fiéis de sua reali- } \\
\text { dade. }\end{array}$ & 0,70 & & & 0,59 & 0,68 \\
\hline $\begin{array}{l}\text { 20. Estabelece relações de apoio aos seus } \\
\text { empregados. }\end{array}$ & 0,63 & & & 0,46 & 0,66 \\
\hline $\begin{array}{l}\text { 23. Designa, a cada empregado, as atribui- } \\
\text { ções que lhes cabem. }\end{array}$ & 0,45 & & & 0,23 & 0,61 \\
\hline $\begin{array}{l}\text { 28. Compreende as perspectivas de seus } \\
\text { empregados. }\end{array}$ & 0,49 & & & 0,56 & 0,74 \\
\hline 29. Age de forma correta. & 0,65 & & & 0,65 & 0,76 \\
\hline $\begin{array}{l}\text { 14. Confia que o empregado se comportará } \\
\text { de forma comprometida a ela no futuro. }\end{array}$ & & 0,60 & & 0,59 & 0,68 \\
\hline $\begin{array}{l}\text { 19. Confia que o empregado se comportará } \\
\text { de forma ética no futuro. }\end{array}$ & & 0,74 & & 0,67 & 0,75 \\
\hline $\begin{array}{l}\text { 21. Confia que o empregado se comportará } \\
\text { de forma leal a ela no futuro. }\end{array}$ & & 0,87 & & 0,59 & 0,82 \\
\hline $\begin{array}{l}\text { 24. Confia que o empregado se comportará } \\
\text { de forma íntegra no futuro. }\end{array}$ & & 0,93 & & 0,76 & 0,85 \\
\hline
\end{tabular}


25. Confia que o empregado cumprirá os acordos e/ou as regras estabelecidas.

26. Confia que o empregado cumprirá as regras de comportamento moral estabelecidas.

27. Confia que o empregado se comportará de forma honrosa no futuro.

3. Evita o alcance dos benefícios próprios, em curto prazo.

5. Ajuda seus empregados sem esperar retribuições por parte deles.

7. Evita vantagens em suas condutas.

15. Evita uma oportunidade conhecida de satisfação, em curto prazo, do autointeresse.

22. Beneficia seus empregados sem esperar retribuições por parte deles.

30. Sacrifica-se pelos seus empregados sem esperar retribuições por parte deles.

\begin{tabular}{lccc}
\hline Autovalores & 13,71 & 2,33 & 1,63 \\
Variância explicada (\%) & 45,70 & 7,76 & 5,43 \\
Alfa de Cronbach & 0,95 & 0,92 & 0,80 \\
Número de itens & 17 & 7 & 6
\end{tabular}

Nota: CIT = correlação item-total.

A análise dos resultados (Tabela 1) indica que o primeiro fator contendo 17 itens apresenta autovalor de 13,71 e 45,7\% de variância explicada. O segundo fator, por sua vez, apresenta autovalor de 2,33 e 7,76\% de variância explicada. Os itens retidos neste fator (7) possuem cargas fatoriais acima de 0,60 e formam unidade semântica. O terceiro fator apresentou autovalor de 1,63 e 5,43\% de variância explicada, formado por seis itens (três correspondentes a dimensão generosidade e outros três itens que respondem à dimensão autocontrole), cujas cargas fatoriais são superiores a 0,42 .

\section{DISCUSSÃO}

O primeiro fator, a partir do item que apresentou a maior carga fatorial (item 10), aponta para um foco na veracidade que deve reger as relações entre indivíduo e organização, bem como os comportamentos da própria organização. $\mathrm{Na}$ composição desse fator constam itens referentes às seguintes dimensões: três itens de amizade, quatro de empatia, três de justiça, três de honestidade, três de veracidade e um de generosidade. $\mathrm{O}$ primeiro fator, denominado Boa-fé organizacional, aproxima-se da investigação de Comte-Sponville (2009) que estabelece uma ligação entre a boa-fé e a veracidade, já que essa virtude moral requer, nas relações com outrem e consigo mesmo, o máximo de verdade e autenticidade e, consequentemente, o mínimo de artifícios ou dissimulações. São exemplos de itens desse fator: "fornece informações fiéis de sua realidade", "age de forma correta", "fornece informações verdadeiras de sua realidade". Conforme Comte-Sponville (2009, p. 214) "a boa-fé é uma sinceridade ao mesmo tempo transitiva e reflexiva", pois a ação (boa-fé) deve ocorrer no próprio sujeito, isto é, a organização deve ser regida e ser sinônimo de transparência, honestidade, idoneidade e integridade nas suas condutas, no fornecimento de informações precisas e verdadeiras, na assistência que dá aos seus empregados e no respeito ao direito do outro.

O exame dos resultados do segundo fator indicou que os sete itens são referentes à dimensão confiança. Denominado Confiança organizacional, este fator está relacionado à percepção do empregado de que a organização confia nele. Essa confiança pode ser observada em itens como "confia que o empregado cumprirá os acordos e/ou regras estabelecidas" e "confia que o empregado cumprirá regras de comportamento moral estabelecidas". Além disso, a análise semântica desse fator também envolve a percepção do empregado de que a organização reconhece que tem com ele um compromisso no futuro, a partir de itens como "confia que o 
empregado se comportará de forma honrosa no futuro" e "confia que o empregado se comportará de forma ética no futuro".

O terceiro fator congregou seis itens (três correspondentes à dimensão generosidade e outros três à dimensão autocontrole). Ao retomar o conceito de generosidade, é possível identificar no ato generoso o interesse pelo outro, enquanto no conceito de autocontrole vale destacar o sacrifício do autointeresse. Ora, se a organização evita o alcance de benefícios, oportunidades e vantagens próprias do seu interesse, pode-se deduzir que apenas o interesse pelo outro esteja em jogo. Pode sugerir ainda que a organização foi movida por uma motivação não egoísta que, mesmo não sendo altruísmo, é uma forma de distanciamento e desprendimento dos próprios interesses. Diante disso, o fator 3 foi denominado Generosidade organizacional, pressupondo uma disposição espontânea da organização em sacrificar seus próprios interesses em prol de necessidades singulares do empregado. São exemplos de itens desse fator: "evita uma oportunidade conhecida de satisfação, em curto prazo, do autointeresse", e "ajuda seus empregados sem esperar retribuições por parte deles".

Dessa maneira, os itens desse fator enfatizam a decisão deliberada da organização em sacrificar-se pelos empregados na ausência de qualquer tipo de retribuição, pagamento ou retorno, a despeito do alcance de seus próprios interesses. Assim, ao evitar a exploração de uma oportunidade conhecida de satisfação do próprio interesse, de alcançar benefícios próprios e de levar vantagens em suas condutas, a organização se esforça para ajudar seus empregados. Com base na literatura revisada e nos resultados empíricos alcançados, a percepção de virtudes morais organizacionais foi definida como um conjunto de crenças do funcionário de que a organização que o emprega tem capacidade de reger suas relações com veracidade, de cumprir compromissos no futuro e de sacrificar seus interesses para o alcance dos interesses dos empregados.

Este estudo teve como objetivo a construção e a busca de evidências de validação de um instrumento de medida de percepção de virtudes morais organizacionais. A construção da medida seguiu os procedimentos de construção e validação de instrumentos elaborados por Pasquali (2003) e pode oferecer aos pesquisadores um instrumento com evidências de validação, contribuindo para as futuras investigações. Embora seja possível afirmar que o objetivo tenha sido alcançado, uma vez que uma escala para mensurar o construto de percepção de virtudes morais organizacionais foi construída e submetida aos procedimentos de validação exploratória, limitações teóricas e metodológicas podem ser salientadas para estudos posteriores.

A respeito das limitações teóricas, pode-se apontar a dificuldade em determinar o número exato das virtudes existentes, o que é aplicável tanto ao indivíduo quanto às organizações (Comte-Sponville, 2009; Ferrell et al., 2001). Soma-se a isso o desafio de transformar termos abstratos em aspectos observáveis. Aliado a isso, no cotidiano, Cameron et al. (2004) sugerem que eventos e fenômenos negativos capturam mais atenção nas relações, emoções e impressões das pessoas do que a ocorrência de emoções boas ou positivas. Em conjunto, esses fatores podem ter contribuído para que os estudos organizacionais não realizassem investigações sistemáticas sobre as virtudes, suas expressões e seus efeitos.

No que se refere às limitações metodológicas, a amostra coletada e utilizada para as análises é formada, em sua maioria, por trabalhadores relativamente jovens e de alta escolaridade, além de ser uma amostra por conveniência. Em vista de maior diversidade metodológica, da continuidade e do aprofundamento das investigações iniciadas por este estudo, algumas sugestões para os estudos futuros são necessárias. Por se tratar de uma conceituação inédita para a literatura, há necessidade de se investigar a multideterminação e a validade prescritiva (ou de critério) do construto (Siqueira, 1995), identificando possíveis antecedentes e consequentes da percepção de virtudes morais organizacionais.

Recomenda-se, ainda, que, em trabalhos futuros, se investigue a validade convergente do construto a partir da adaptação de outros instrumentos, como aqueles citados na fundamentação teórica deste trabalho. Essas sugestões se constituem como uma promissora agenda de pesquisa, já que extrapolam não só o escopo editorial deste periódico, mas também os objetivos primários desta investigação. Estudos com novas amostras, assim como o uso de análises confirmatórias, representam um avanço necessário no desenvolvimento dessa medida.

Para um maior refinamento conceitual e empírico do construto, sugere-se a sua investigação por meio de estudos qualitativos que perscrutem, entre os trabalhadores, o conceito aqui proposto. Por fim, recomenda-se que estudos posteriores procurem estabelecer a relação entre a percepção de virtudes morais organizacionais e os vínculos normativos - como o comprometimento organizacional normativo - dos empregados com as organizações. Assim, para maior entendimento do vínculo moral estabelecido entre indivíduo e organização, sugere-se, ainda, a investigação sobre se a percepção de virtudes morais na organização cria um sentimento de 
lealdade e de dívida social para com ela, e se isso pode ser um determinante na permanência, na assiduidade e no desempenho do empregado. Aspectos como comportamento de cidadania organizacional, comportamento pró-social, resiliência, fatores culturais e outros construtos estudados mais recentemente pela psicologia positiva podem ser alvos de investigação em relação à percepção de virtudes morais organizacionais. Espera-se que a medida proposta por este estudo possa contribuir para um maior avanço na investigação e nos estudos no campo do comportamento organizacional, notadamente aqueles que envolvam bases morais do comportamento.

\section{REFERÊNCIAS}

Aristóteles. (2006). Ética a Nicômaco (1a ed., P. Nasseti, Trad.). São Paulo: Martin Claret.

Arruda, M. C. C., Whitaker, M. C., \& Ramos, J. M. R. (2009). Fundamentos da ética empresarial e econômica (4a ed.). São Paulo: Atlas.

Cameron, K., Bright, D., \& Caza, A. (2004). Exploring the relationships between organizational virtuousness and performance. American Behavioral Scientist, 47(6), 1-24. doi: 10.1177/0002764203260209

Comte-Sponville, A. (2009). Pequeno tratado das grandes virtudes (2a ed., E. Brandão, Trad.). São Paulo: Martins Fontes.

Enzmann, D. (1997). RanEigen: A program to determine the parallel analysis criterion for the number of principal components. Applied Psychological Measurement, 21(3), 232. doi: 10.1177/01466216970213003

Ferrell, O. C., Fraedrich, J., \& Ferrell, L. (2001). Ética empresarial: Dilema, tomadas de decisões e casos (4a ed., R. Jungmann, Trad.). Rio de Janeiro: Reichmann \& Affonso.

Fonseca, H. (2011, Julho 12). Virtudes morais despertam interesse das empresas. Recuperado de http://www.bemparana.com.br/ noticia/185204/virtudes-morais-despertam-interesse-das-empresas.

Gavin, J. H., \& Mason, R. O. (2004). The virtuous organization: The value of happiness in the workplace. Organizational Dynamics, 33(4), 379-392. doi: http://dx.doi.org/10.1016/j.orgdyn.2004.09.005

Gomide, P. I. C. (2011). Comportamento moral: Uma proposta para o desenvolvimento das virtudes. Curitiba: Juruá.

Hair, J. F., Anderson, R. E., Tatham, R. L., \& Black, W. C. (2005). Análise multivariada de dados (5a ed.). Porto Alegre: Bookman.

Hamrahi, M., Najafbagy, R., Musakhani, M., Daneshfard, K., \& Delavar, A. (2015). Factor effecting on promoting organizational virtuousness in Iran state agencies. Indian Journal of Fundamental and Applied Sciences, 5(1), 4772-4779.

Harman, H. H. (1967). Modern factor analysis. Chicago: The University of Chicago Press.

Kooshki, S. A., \& Zeinabadi, H. (2015). An investigation into the role of organizational virtuousness in the job attitudes of teachers. Journal UMP Social Sciences and Technology Management, 3(1), 563-570.

Laros, J. A. (2004). O uso da análise fatorial: Algumas diretrizes para pesquisadores. In L. Pasquali (Org.), Análise fatorial para pesquisadores (pp. 163-193). Petrópolis, RJ: Vozes.

La Taille, Y. (2001). Desenvolvimento moral: A polidez segundo as crianças. Cadernos de Pesquisa, 114, 89-119. doi: http:// dx.doi.org/10.1590/S0100-15742001000300004

La Taille, Y. (2002). A questão da indisciplina: Ética, virtudes e educação. In P. Demo, Y. La Taille \& J. Hoffmann (Orgs.), Grandes pensadores em educação: O desafio da aprendizagem, da formação moral e da avaliação (pp. 67-98). Porto Alegre: Mediação.

MacIntyre, A. (2001). Depois da virtude: Um estudo em teoria moral (2a ed., J. Simões, Trad.). São Paulo: EDUSC.

Meyer, J. P., Stanley, J. D., Herscovitch, L., \& Topolnytsky, L. (2002). Affective, continuance, and normative commitment to the organization: A meta-analysis of antecedents, correlates, and consequences. Journal of Vocational Behavior, 61(1), 20-52. doi:10.1006/jvbe.2001.1842

Moore, G., \& Beadle, R. (2006). In search of organizational virtue in business: Agents, goods, practices, institutions and environments. Organization Studies, 27(3), 369-389. doi: 10.1177/0170840606062427

Pasquali, L. (1999). Instrumentos psicológicos: Manual prático de elaboração. Brasília: LabPAM/IBAPP.

Pasquali, L. (2003). Psicometria: Teoria dos testes na psicologia e na educação. Petrópolis: Vozes.

Pieta, M. A. M. (2009). A expressão do sentimento de gratidão: Um estudo com crianças e adolescentes escolares de Porto Alegre (Dissertação de mestrado). Recuperado de http://www.lume.ufrgs.br/handle/10183/15871 
Ribeiro, N., \& Rego, A. (2010). Como as percepções de virtuosidade organizacional explicam o empenhamento e os comportamentos de cidadania organizacional. Anais do VII Simpósio Nacional de Investigação em Psicologia. Braga: Universidade do Minho. Recuperado de http://www.academia.edu/2243486/Como_as_Percep\%C3\%A7\%C3\%B5es_de_ Virtuosidade_Organizacional_Explicam_o_Empenhamento_e_os_Comportamentos_de_Cidadania_Organizacional

Sertek, P., \& Reis, D. (2002). Gestão de mudanças e comportamento ético nas organizações. Anais do Congresso Anual da Sociedade Brasileira de Gestão do Conhecimento. São Carlos: Universidade Federal de São Carlos.

Siqueira, M. M. M. (1995). Antecedentes de comportamentos de cidadania organizacional: A análise de modelo pós-cognitivo (Tese de doutorado não publicada). Universidade de Brasília, Brasília.

Srour, R. H. (2000). Ética empresarial: Posturas responsáveis nos negócios, na política e nas relações pessoais (8a ed.). Rio de Janeiro: Campus.

Ugwu, F. O. (2012). Are good morals often reciprocated? Perceptions of organizational virtuousness and optimism as predictors of work engagement. Asian Journal of Social Sciences \& Humanities, 1(3), 188-198.

Vásquez, A. S. (1997). Ética (17a ed., J. Dell'Anna, Trad). Rio de Janeiro: Civilização Brasileira.

Wright, T. A., \& Goodstein, J. (2007). Character is not "dead" in management research: A review of individual character and organizational-level virtue. Journal of Management, 33(6), 928-958. doi: 10.1177/0149206307307644 